\title{
A PARTIAL TEST AND DEVELOPMENT OF DELONE AND MCLEAN'S MODEL OF IS SUCCESS ${ }^{3}$
}

\author{
Peter B. Seddon \\ Department of Information Systems, The University of Melboume \\ Min-Yen Klew \\ Rating Agency Malaysia Berhad, Kuala Lumpur.
}

\begin{abstract}
DeLone and McLean's (1992) comprehensive review of different information system success measures concludes with a model of interrelationships between six IS Success constructs. This paper critically examines the meaning of four of these constructs and the evidence of relationships between them. It then provides results from empirical tests of these relationships. Tests are conducted using both conventional ordinary least squares regression path analysis and structural equation modeling -- with substantially similar results.

The empirical results provide substantial suppon for the "up stream" two thirds of DeLone and McLean's model. Three factors. System Quality, Information Quality, and Usefulness, are found to explain 75\% of the variance in the overall User Satisfaction measure. The empirical results also provide substantial support for the use of Usefulness as an IS Success measure, and of the hitherto-unreported importance of "Importance of the task" in user perceptions of IS Usefulness.
\end{abstract}

Key Words and Phrases: information system success, user satisfaction, perceived usefulness, importance of task, information quality, ease of use.

\section{INTRODUCTION}

DeLone and McLean's (1992) comprehensive review of different information system success measures makes two important contributions to our understanding of Information System (IS) success. First, it provides a scheme for classifying the multitude of IS success measures that have been used in the literature into six categories. Second, it suggests a model of interdependencies between these categories. Commenting on their Figure 2, reproduced here as Figure la, DeLone and McLean say (p.88):

The $\mathrm{U} / \mathrm{S}$ success model proposed in Figure 2 is an attempt to reflect the interdependent, process nature of US success. Rather than six independent success categories, there are six interdependent dimensions to U/S success. This success model clearly needs further development and validation before it could serve as a basis for the selection of appropriate $\mathrm{L} / \mathrm{S}$ measures.

The last sentence in the above quotation provides the motivation for this paper. We do not address the two right-hand constructs ${ }^{4}$ but we do examine the meaning of, and relationships between, the other four.

\footnotetext{
${ }^{3}$ Acknowledgments: The authors with to thank participants at workshops at The University of Melboume, Curtin University, University of British Columbia, Michigan State University, and the Intemational Conference on Information Systems, Vancouver, December, 1994 for the suggestions regarding earlier versions of this paper. Comments from the four reviewers for the ICIS 94 conference also improved this paper considerably. Finally, thanks to all those who responded to the survey, and so made this study possible. ${ }^{4}$ Melone (1990) provides a detailed discussion of the relationships between use, satisfaction, and IS effectiveness that considers the right-hand constructs in Figure la in more depth. At the empirical level, Goodhue and Thompson (1995) explore links between IT use and job performance.
} 


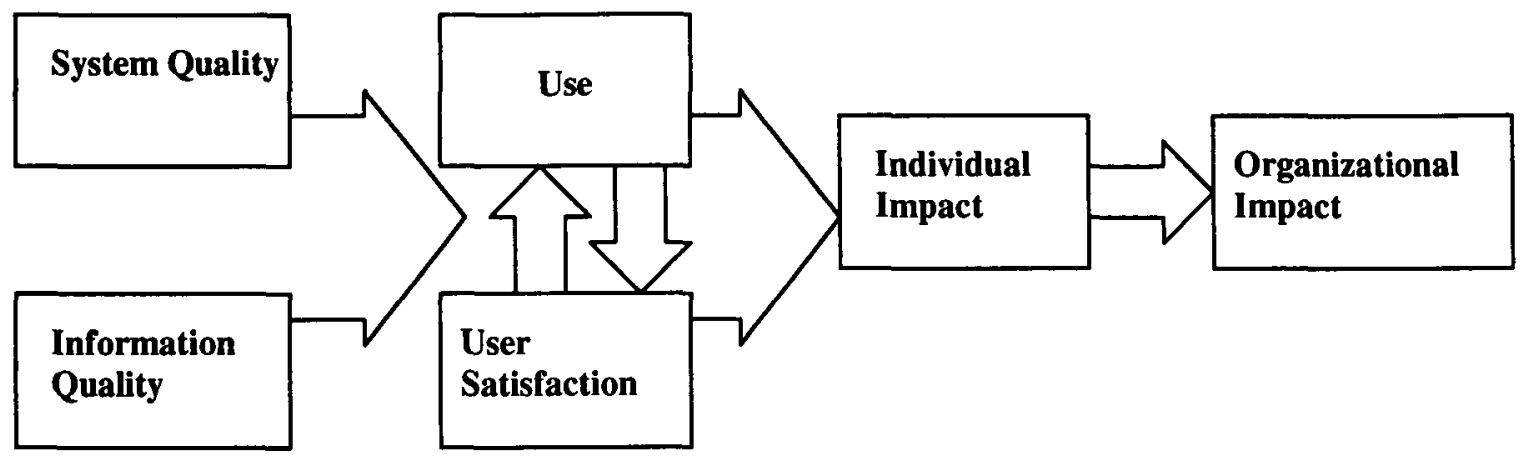

Figure 1a: DeLone and McLean's Model of IS Success

(DeLone and McLean (1992), Figure 2, p.87)

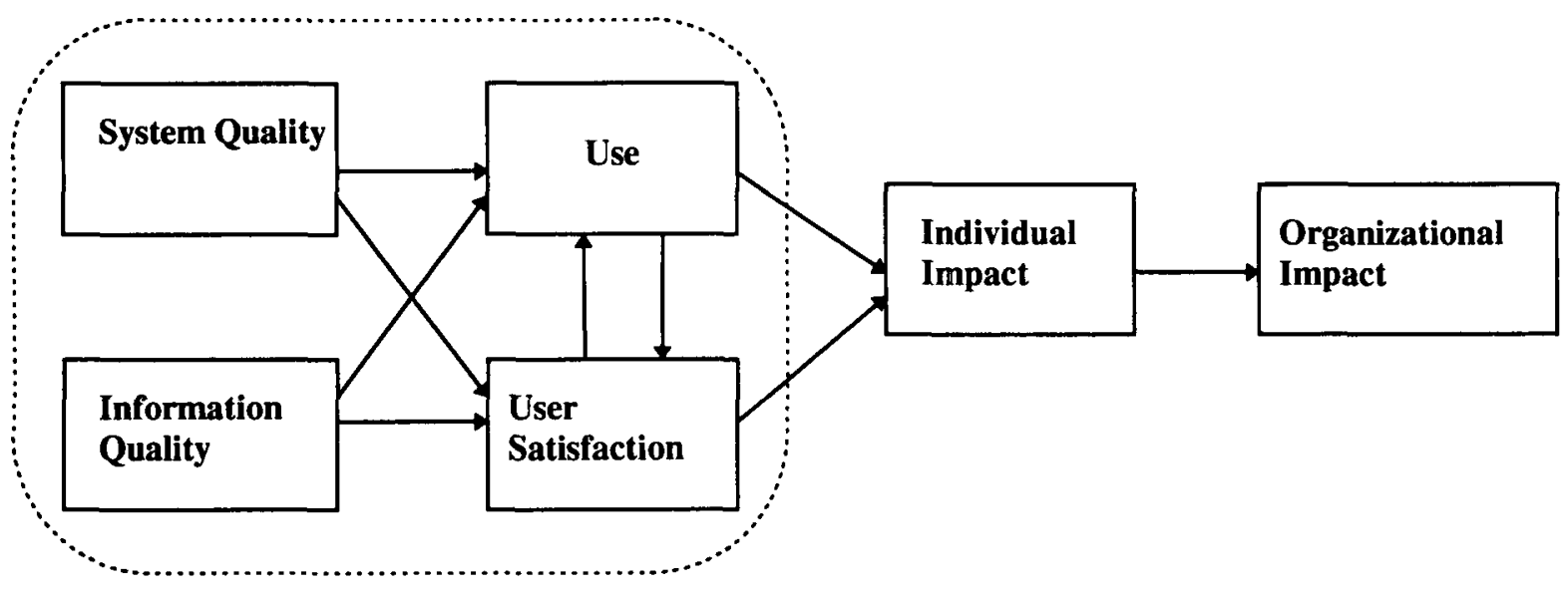

Figure 1b: Path Model that seems to be implied by DeLone and McLean's Model

If the six categories of IS success measure in Figure 1a are treated as variables, the causal model implied by DeLone and McLean's paper is as shown in Figure 1b. Each line in Figure 1b is, in effect, an hypothesis about an independent causal relationship between the constructs in the model. Thus the dotted-line box in Figure $1 \mathrm{~b}$ contains six hypotheses (six arrows on the path diagram) linking the four success measures System Quality, Information Quality, Use, and User Satisfaction. This paper provides an empirical test of relationships between these four variables as perceived by over one hundred users of one specific information system. For reasons given below, the model actually tested is as shown in Figure 2. The three differences between DeLone and McLean's model (Figure 1b) and the model tested (Figure 2) are as follows:

(a) Use in DeLone and McLean's model has been replaced by Usefulness;

(b) a new variable, System Importance, has been added to DeLone and McLean's model to help explain variations in users' perceptions of Usefulness and User Satisfaction;

(c) the simultaneous causality between Use and User Satisfaction in DeLone and McLean's model has been replaced by one-way causality, i.e., we argue that Usefulness causes User Satisfaction, not vice versa. 
H6

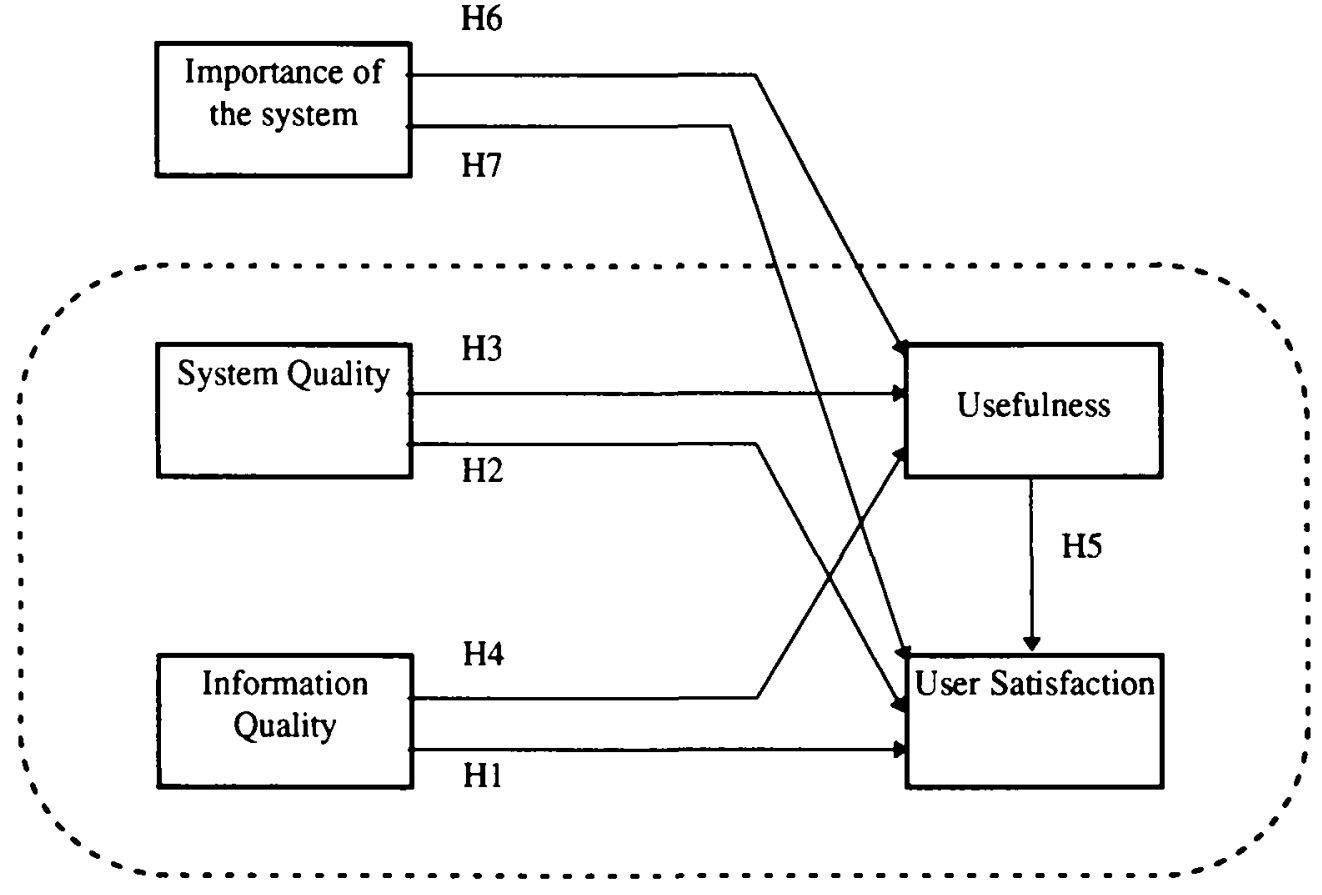

Figure 2: The Model of User Satisfaction Tested in this Study

(This is a slightly modified version of the variables within the dotted box in Fig. 1b. Use has become Usefulness, and Importance of the system has been added.)

The meaning of the five constructs used in Figure 2, and the theory supporting the relationships between them, are discussed in the second section of this paper (the next section). To test the model, data were collected from 104 users of a university's departmental accounting system. Discussion of methodology used for testing the model, measurement of variables, and test results are presented in the third section of this paper. The model is analyzed using both conventional ordinary least squares (OLS) linear regression and using a LISREL-like structural equation modeling (Bollen 1989; Jöreskog and Sörbom 1988) package called Amos ${ }^{5}$ (Arbuckle, 1994a). Finally, the paper concludes with a brief discussion of the implications of these results for the measurement of IS success in future research.

Our conclusions are that (a) there is substantial support for the up-stream side of DeLone and McLean's model, (b) of the four measures examined, User Satisfaction is the most general individual-user perceptual measure of information system success, and (c) future researchers will need to control for Task Importance whenever they measure the Usefulness of an information system (because systems that perform more important tasks are perceived as more useful, irrespective of the quality of the actual system).

\section{DEFINING CONSTRUCTS AND THEORIZING ABOUT THEIR RELATIONSHIPS}

\section{Replacing $U s e$ in Figure 1 by Usefulness in Figure 2}

As reported by DeLone and McLean (1992), many researchers have used Use as an objective measure of system success. The implication is that if a system is used, it must be useful, and therefore successful. However, non-use does not necessarily mean a system is not useful, it may simply mean that the potential user has other more pressing things to be done. In addition, as DeLone and McLean point out, "usage, either

\footnotetext{
5 Amos stands for "Analysis of Moment Structures".
} 
perceived or actual, is only pertinent when such use is voluntary" (p.68). When usage is compulsory, the number of hours a system is used conveys little information about system usefulness, and so success.

Reflecting on the relevance of Use as an indicator of system success in some situations and its irrelevance in others, we conjectured that the underlying success construct that researchers have been trying to tap is Usefulness, not Use. Use is a good proxy for Usefulness in situations where a tool is used, and use is not mandatory. It then provides a simple objective measure of success. However, in cases where a system is not used during the period of study, or where usage is mandatory (as in the accounting system examined in this study), we argue that Usefulness continues to be a meaningful measure of success, even though Use does not. We therefore decided to measure Usefulness, not Use, in our test of DeLone and McLean's model (Figure 2) ${ }^{6}$.

\section{The First Four Hypotheses in Figure 2 (H1-H4)}

The first four (independent) hypotheses to be tested in this paper follow directly from DeLone and McLean's model:

H1: Increases in Information Quality will cause increases in User Satisfaction

H2: Increases in System Quality will cause increases in User Satisfaction

H3: Increases in System Quality will cause increases in Usefulness

H4: Increases in Information Quality will cause increases in Usefulness

There are four constructs involved. Information Quality is concerned with such issues as the timeliness, accuracy, relevance, and format of information generated by an information system. System Quality is concerned with whether or not there are "bugs" in the system, the consistency of the user interface, ease of use, response rates in interactive systems, documentation, and sometimes, quality and maintainability of the program code. Usefulness of an IS is "the degree to which a person believes that using a particular system would enhance his or her job performance" (Davis 1989). Satisfaction is "the result of the individual taking outcomes that have been received and evaluating them on a pleasant-unpleasant continuum" (Naylor et al. 1980).

There is quite strong support in the literature, both theoretical and empirical, for hypotheses H1-H4. A brief summary of seven relevant studies follows.

First, based on the work of Bailey and Pearson (1983), Ives et al. (1983) discuss the development of two instruments for measuring User Satisfaction. The longer of these instruments was factor analyzed into five factors: EDP Staff and Services, Information Product 1, Vendor Support, Information Product 2, and Knowledge or Participation. The shorter instrument -- later validated by Baroudi and Orlikowski (1988) -factor analyzed into three factors: EDP Staff and Services, Information Product, and User Knowledge or Participation. A number of researchers have been critical of the use of these multi-factor measures of user satisfaction. Treacy (1985) described the factors as "imprecise and ambiguous". Galletta and Lederer (1989) argued that because of the heterogeneity of the items, results from the Ives et al. (1983) instruments should be "interpreted with caution". Our explanation of the factors that emerge from the Ives et al. instruments is that they measure the independent variables that Bailey and Pearson (1983) and Ives et al. (1983) thought were likely to cause Satisfaction, not User Satisfaction itself. In particular, we view the presence of so many questions about information quality in the Ives et al. User Satisfaction instruments as providing theoretical support for hypothesis 1 in Figure 2.

Second, in a recent empirical study, Seddon and Yip (1992) constructed a four-item instrument that attempts to measure User Satisfaction directly. This they compared with the factors from Ives et al.'s Short Form instrument. Seddon and Yip found that for users of computer-based accounting systems, factors such Information Quality, Usefulness, and User Knowledge of various system features explained over $70 \%$ of the variance in their User Satisfaction measure. The t-statistics in their regression 7.3 (p.89) indicate that

\footnotetext{
${ }^{6}$ Correlations between $U$ se and Usefulness are reported later in the paper, in Table 2.

${ }^{7}$ Ives et al. actually used the term "Involvement" not "Participation". To avoid confusion with Barki and Hartwick's (1989) User Involvement, a construct that is closely related to the System Importance construct used in hypotheses 6 and 7, we have renamed the Ives et al. term "User Participation" in this paper.

${ }^{8}$ These four questions (as they apply to DAS, the system for which data were collected for this study) are reproduced in Appendix 2 to this paper, Section C.

${ }^{9}$ Such high correlations of multi-factor measures and overall satisfaction measures are not uncommon. Bailey and Pearson (1983, p.536) report a correlation of 0.79 between their normalized importance-weighted measure of user satisfaction (based on up to 39 questions) and their single-scale measure of Overall "Self-assessed" Satisfaction.
} 
Information Quality (t-statistic=7.48) is an important determinant of Satisfaction. This provides strong empirical support for hypothesis 1 in Figure 2.

Third, Doll and Torkzadeh (1988) developed a measure of End User Computing Satisfaction (EUCS) that asked ten questions about Information Quality and two about Ease of Use. These questions factor analyzed into five factors. The first four factors relate to the construct that we call Information Quality: Information Content, Accuracy, Format, Timeliness. The fifth factor is Ease of Use, a component of System Quality. As with the Ives et al. instruments, we contend that Doll and Torkzadeh's instrument is actually measuring two variables that are causes of User Satisfaction. Thus as with the Ives et al. instrument, we view Doll and Torkzadeh's decision to include questions concerning Information Quality and System Quality in their measure of End User Computing Satisfaction as providing theoretical support for hypotheses 1 and 2 in Figure 2.

Fourth, in their empirical study, Seddon and Yip (1992) report that Doll and Torkzadeh's EUCS explained over $70 \%$ of the variance in their four-item User Satisfaction measure, but that after Information Quality was included in the regression, Ease of Use was not significant (regression 7.2). This provides further empirical support for hypothesis 1 , but not for hypothesis 2 .

Fifth, Davis (1989) has provided IS researchers with two highly reliable measures of Perceived Usefulness and Ease of Use. Davis was interested in explaining peoples' ex ante decisions to use information technology, but the measures seem equally applicable to ex post evaluations of information systems. Concerning Ease of Use (an important component of System Quality), Davis found significant correlations $(\mathrm{p}<0.001)$ between Ease of Use and Usefulness for three of four systems studied (Table 8, p.332), and suggests that "ease of use influences usage indirectly through its effect on usefulness" (p.330). Davis's work provides both theoretical and empirical support for hypothesis 3 in Figure 2 (i.e., that increased System Quality is associated with increased Usefulness).

Sixth, in support of hypothesis 4, Larcker and Lessig (1980, p.123), Franz and Robey (1986), and Kraemer, Danzinger, Dunkle, and King (1993, Q.2a, p.133) have all argued that increased Information Quality will lead to increased Usefulness. Franz and Robey (1986) include two questions in their Perceived Usefulness instrument (p.353) that suggest they think higher Information Quality implies higher Usefulness. The first question asks: "To what extent does this system overload you with more data than it seems you can possibly use?". The second asks: "To what extent does this system provide report(s) to you that seem to be just about exactly what you need?". The comments from Larcker and Lessig and Kraemer et al., and the inclusion of the two questions just cited in Franz and Robey's questionnaire all provide theoretical support for hypothesis 4 in Figure 2.

Seventh, Kraemer et al. (1993) studied factors that influence the perceived usefulness of computer-based information (CBI). They used regression analysis to assess the relative importance of factors that affect usefulness. For data from 211 operations managers in public organizations, they report: "Finally, from the foregoing factors, CBI accessibility, CBI quality, and reliance on experts were found to have the most significant influence on the perceived usefulness of CBI" (p.139). This provides limited empirical support for hypothesis $4^{10}$.

\section{Usefulness Causes User Satisfaction, Not Vice Versa (H5)}

DeLone and McLean's model (Figure 1a) suggests that there is a two-way causal relationship between Use and Satisfaction. A simple duplication of this two-way relationship in Figure 2 would imply a two-way causal relationship between Usefulness and Satisfaction. Is this valid, or does the change from the Use construct to Usefulness introduce a subtle change in the causality relationships? As we could think of no statistical test to determine whether Usefulness causes Satisfaction, or vice versa, we were forced to resort to semantics to try to answer this question. The conclusions from this back-to-first-principles analysis are presented in the next two paragraphs.

Something is useful if it provides future benefits ${ }^{11}$. A car is useful for getting to work. A bicycle is less useful for the same task because it goes slower and you may get wet if it rains. A car that won't start is not useful for getting to work today, but it will be useful again in the future once someone has got it working. A bicycle is not

\footnotetext{
${ }^{10}$ Support is "limited" because in addition to asking questions similar to our questions Q.6, 7, 8, and 9 on Information Quality (see Appendix 2) under the heading "Information Quality", Kraemer et al. also asked whether "the computer makes new information available to me that was not previously available". This idea, which was absent from our study, appears to have been the most significant factor in Kraemer's regression (their Table 7, p.141).

${ }^{11}$ Davis (1989, p.320) expresses the same idea when he says something is useful if it is "capable of being used advantageously".
} 
useful for getting to work today if you don't know how to ride. Consistently, across many examples, we found that Usefulness is concerned only with the future benefits of performing some task. Costs are much less important. For instance, your new $\$ 30,000$ automobile may be judged to be marginally more useful than the reliable old $\$ 6,000$ automobile it replaced, but not by five times. The benchmark for judging usefulness of a tool is that the value of the benefits flowing from its use in some specific task must exceed zero.

The benchmark for judging satisfaction is different. User Satisfaction is the net feeling of pleasure or displeasure that results from aggregating all the benefits that a person hopes to receive from interaction with the information system. Each user has a set of expected benefits or aspirations for the information system. To the extent that the system meets or fails to meet each of these aspirations, the user is more or less satisfied. At a minimum, a tool is expected to be useful. Beyond that, the more useful the tool, the more likely the user is to be satisfied with it. However, satisfaction reflects a wider set of expected benefits or aspirations than mere usefulness. For instance, we are more likely to be satisfied with our new $\$ 30,000$ automobile than with the old $\$ 6,000$ one, even though the annual cost of ownership is much higher. Assuming the new car is only marginally more useful than the old, this example implies that we must be valuing other non-usefulness benefits (such as comfort and status) in determining satisfaction.

Considerations along these lines lead us to believe that increases or decreases in Usefulness will lead to increases or decreases in User Satisfaction with information systems, but not vice versa (because some increases in Satisfaction are unrelated to Usefulness). This is the basis for hypothesis 5 in Figure 2:

\section{H5: Increases in Usefulness will cause increases in User Satisfaction}

In effect, we regard DeLone and McLean's model as saying that User Satisfaction responds primarily to three types of aspirations that people have for information systems: people want their information systems to provide high quality information (H1), to be of high quality (H2), and to be useful in their jobs (H5).

What support is there in the literature for the hypothesis that Usefulness causes Satisfaction, but not vice versa? Whilst many researchers have studied the relationship between Use (a behaviour) and Satisfaction (an attitude), DeLone and McLean's model is concerned with Use as a measure of success, i.e., with Usefulness (a belief) ${ }^{12}$. Surprisingly few researchers have considered the relationship between Usefulness and Satisfaction. Apart from Bailey and Pearson (1983), who used a question about Utility (the relative balance between cost and usefulness) in their measure of Satisfaction, and Goodhue (1986), who speculated that there might be weak links in both directions between Satisfaction and Usefulness, the most helpful study we could find was by Franz and Robey (1986). Franz and Robey used Perceived Usefulness as the dependent variable in their study of user participation and organizational context. In discussing the choice of independent variable, they say:

Our questions were designed to assess perceptions of usefulness rather than more-general attitudes [Robey 1979; Schewe 1976] or satisfaction [Bailey and Pearson 1983; Ives et al. 1983] (p.338).

It is clear from this sentence that they believe that Satisfaction is a more general concept than Usefulness. However, it is not clear how they think the two concepts are related. Since Franz and Robey's was the only study we could find that offered clear insights into the relationship between Usefulness and User Satisfaction, we were forced to rely on the "first-principles" analysis above to justify our interpretation of the arrows in DeLone and McLean's model, i.e., to justify hypothesis 5.

\section{System Importance used to Explain Variance in Usefulness and User Satisfaction (H6 and H7)}

Because DeLone and McLean's model was proposed as a way of interrelating various measures of IS success, it does not consider factors that might influence peoples' evaluations of success. However, as all four constructs in the dotted line box in Figure 2 are perceptual, it seems highly likely that users' opinions about the relevance of the system to their own goals and aspirations will influence their opinions about the value and so success of the system. For example, if what the system does is unimportant to the user, there seems little chance that the user will perceive the system as useful, no matter how well designed it is, or how easy it is to use. Conversely, if the task the system supports is perceived as very important, a poor system may be perceived as useful, even if it is quite user unfriendly. In this study of success measures, it therefore seems essential to consider the interests of the individuals being asked to evaluate the information system.

How should users' interests be incorporated into Figure 1b? For help in this regard, we turned to Barki and Hartwick's notion of User Involvement. Barki and Hartwick's (1989) revolutionary paper presents a strong

\footnotetext{
${ }^{12}$ Goodhue (1986) makes the point that Usefulness (which he calls IS Satisfactoriness) is a belief (a relatively objective judgment about whether a tool can assist with the job), whereas Satisfaction is an attitude (a "predisposition to respond favorably or unfavorably to" the system (Melone 1990)).
} 
case for distinguishing between User Participation, which they define as "participation in the system development process" (p.53), and User Involvement, which they define as "the subjective psychological state" of the user "when he or she considers a system to be both important and personally relevant" (p.53). This User Involvement concept is very similar to task-relevance concept we had in mind, so we adopted the Importance component of User Involvement for our study.

Intuitively, we felt that people who believed that the task performed by the system was important would also perceive the system that performed it to be useful. The more important the task, the more useful the system. Thus $\mathrm{H} 6$ proposes that the greater the user's perception of the Importance of the task, the more useful the system will be perceived to be. Additional support for $\mathrm{H} 6$ comes from Larker and Lessig (1980, p.123), in the context of information usefulness. Larker and Lessig used the term "Perceived Importance" to refer to "the quality that causes a particular information set to acquire relevance to a decision maker". Consistent with our H6, they go on to argue that Perceived Importance will "tend to increase the perceived usefulness of the set".

The link from Importance of the task to Satisfaction is less clear. Provided the system works, the more important the task to the user, the more satisfied he or she is likely to be (Importance up, Satisfaction up). On the other hand, if the system does not work and the task is important, the user may be very dissatisfied (Importance up, Satisfaction down). Finally, if the task is unimportant, the user's threshold for satisfaction may be so low (i.e., the user would be indifferent to the system) that satisfaction scores might be moderate (Importance down, Satisfaction indeterminate). These last two scenarios would reduce correlations between Importance and User Satisfaction. On balance, since the system we proposed to test did work (though not very well) we expected the correlation to be positive. This is the basis for $\mathrm{H} 7$ in this study.

Perceptions of System Quality and Information Quality are less likely to be coloured by perceptions of system Importance than perceptions of Usefulness and Satisfaction. For instance, twenty years ago, card-punch machines were the normal everyday way of communicating with computers. They were easy to use, and they were useful. Today, they are no less easy to use, but now that card decks are no longer used for communicating with computers, card-punch machines are considered useless. Based on this analogy (in which Usefulness changes as Importance changes but Ease of Use does not), we argue that System Quality (of which Ease of Use is a central component) is unlikely to be influenced by the importance of the system to the user, i.e., System Importance.

Similarly, we argue that Information Quality is unlikely to be influenced by System Importance. Information Quality is concerned with the timeliness, accuracy, relevance, and format of information generated by an information system. These are relatively objective qualities of information, and it seems unlikely that a user will judge Information Quality to be high simply because he or she thinks the task performed by the system is important.

We therefore expect System Importance will be positively associated with both Usefulness and Satisfaction but not with System Quality and Information Quality. These expectations are shown as bypotheses 6 and 7 in Figure 2.

H6: Increases in System Importance will cause increases in Usefulness

H7: Increases in System Importance will cause increases in User Satisfaction

Surveying the literature for support for these hypotheses, we found two papers of particular interest. First, in the empirical study, Jackson, Chow, and Leitch (1993) studied factors affecting behavioural intention to use an information system. They used Zaichkowski's (1985) Involvement instrument to measure User Involvement, and found a highly significant relationship between User Involvement and Perceived Usefulness (t-statistic = 6.52). There are some difficulties with the use of all items in Zaichkowski's Involvement instrument in testing the relationship between User Involvement and Usefulness because some items in Zaichkowski's instrument actually measure Usefulness directly. Nonetheless, the large t-statistic in the Jackson et al. (1993) study provides considerable empirical support for the use of User Involvement, hence Importance ${ }^{13}$ to explain variance in Perceived Usefulness (H6).

\footnotetext{
${ }^{13}$ Recall that Importance and Personal Relevance are the two major components of Barki and Hartwick's User Involvement.
} 
Second, Kappelman and McLean (1991), used the same Zaichkowski instrument to investigate the relationship between User Involvement and User Satisfaction. They report a highly significant association $(\mathrm{p}<0.001)$. This provides empirical support for our hypothesis 7.

\section{TESTING THE MODEL OF USER SATISFACTION SHOWN IN FIGURE 2}

\section{The Questionnaire}

To test the model in Figure 2, we prepared a questionnaire based on a number of standard instruments. The questionnaire was to be administered to all users who had completed the training course for our university's recently-implemented Departmental Accounting System, DAS. Details of all questions used in measuring variables for this study are presented in Appendix 2. There are six groups of questions that measure seven variables as follows. First, the eight questions on System Quality are based on Doll and Torkzadeh's (1988) two questions on Ease of Use, four of Davis's (1989) questions on Perceived Ease of Use ${ }^{14}$, plus three additional questions -- all phrased in present (not future) tense ${ }^{15}$. Second, the ten questions on Information Quality are all from Doll and Torkzadeh (1988). Third, the four questions on Overall Satisfaction are from Seddon and Yip (1992). Fourth, the six questions on Perceived Usefulness are from Davis (1989).

Fifth, the five questions on System Importance are from Zaichkowski (1985) via Kappelman and McLean (1991). Data for this study were collected before Barki and Hartwick (1994) published their instruments for measuring User Involvement, so we did not use their instrument for measuring Importance. However, because respondents answered all 14 questions from Kappelman and McLean (1991), it was possible to construct a measure very similar to Barki and Hartwick's. In fact, three of their five Importance questions and one of their four Personal Relevance questions (1994, Table 2a, p.70) are included in our five-item Importance measure.

Finally, the last two variables used in this study are Use if not mandatory and IS Use $\%^{16}$. Single questions to measure these two variables were included to test the relationships between Use (the variable required in DeLone and McLean's model) and Usefulness (the variable that we argued earlier would be more relevant in situations where usage was mandatory). Use if not mandatory is a hypothetical intention-to-use measure because it asked users to pretend that usage of DAS was not mandatory. Based on tests of Davis's Technology Acceptance Model (TAM) (Davis (1989, 1993), Davis et al. (1989), Adams et al. (1992), Segars and Grover (1993), and Igbaria et al. (1995)) one would expect quite a high correlation between Usefulness and Use if not mandatory. IS Use \% measures self-reported actual use of DAS. Because some respondents were part time, IS Use \% is measured as a percentage of the respondent's average working week.

\section{Details of the System and Its Users}

As noted above, the system we chose for testing the model in Figure 2 was the university's recentlyimplemented Departmental Accounting System, DAS. We chose this particular system because we knew there had been some difficulties with its implementation, and a wide range of Usefulness and Satisfaction scores was likely ${ }^{17}$. A second attraction was that the same system was in use in all departments, and all users had been trained by the same trainers. There were therefore a smaller number of extraneous factors that could cause variance in the Usefulness and Satisfaction scores.

The goal of DAS is to keep track of all of each department's diverse range of income and expenditure, so that those who are managing various projects, research grants, etc., can know, at any time, how much money they have left to spend. Built in Ingres at a fully-implemented cost of over $\$ 500,000$, DAS runs on a central computer and acts as a front end to the university's central accounting system. About half the implementation cost was for user training and support during the two- year phased implementation of the system. The typical DAS user is a relatively senior clerical officer in each department or faculty office who uses the system for about 4-5 hours per week for maintaining the department's accounting records. At the time of the survey, 169

${ }^{14}$ The question on DAS being "easy to use" is common to both Doll and Torkzadeh (1988) and Davis (1989).

${ }^{15}$ Note that these questions about System Quality are all based on Perceived Ease of Use. Since the same system is being used by all users, the objective technical characteristics of the system are the same for all users, so there was no point asking questions about technical aspects of system quality.

${ }^{16}$ These variables are based on questions 1 and 3 in Section F of Appendix 2.

${ }^{17}$ This opinion proved to be correct. Mean User Satisfaction scores for data from this study were 4.68 (s.d. 1.57) on a scale from 1 to 7. Mean scores when Seddon and Yip (1992) used the same instrument to measure User Satisfaction with commercial general ledger systems was 5.56 (s.d. 1.16). Our users were significantly less satisfied. 
people had completed the DAS training course: 152 were women, 17 were men; 118 were accessing DAS through Apple MacIntosh computers in their departmental offices, and 51 from IBM PCs.

\section{Data Collection}

After ten face-to-face trials, the questionnaire was mailed to the remaining 159 trained DAS users. 134 questionnaires were returned, but only 94 were useful for data analysis. Non-useable responses were for the following reasons: some departments were not yet using DAS, some trained users were on leave, some were no longer responsible for DAS, and some had resigned. Combining the 10 initial responses with the 94 returned by mail gave 104 responses for statistical analysis ${ }^{18}$. For each of the 35 questions asked, responses from early and late respondents ( 83 and 21 respondents, respectively) were compared using the Mann-Whitney U statistic (Siegel and Castellan 1988). None of the U statistics from these 35 questions indicated a significant difference, at the 5\% level, between early and late respondents. Because of the high response rate and the lack of significant differences between early and late respondents, non-response bias is not considered a problem for this study.

Descriptive statistics for distributions of responses for each variable are given in Table 1. Principal components factor analysis (no further details in this paper) of the eight questions on System Quality showed that one question (question 7 in Appendix 2) had a loading of only 0.25 on the main factor. It was therefore deleted, and all statistics that follow are based on the remaining seven-item measure of System Quality. Reliabilities (Cronbach alpha) and the Pearson correlation matrix for the variables used in the study are shown in Table 2.

Was it incorrect to argue (as we did in the previous section) that Usefulness should be used in place of Use in DeLone and McLean's model? The answer to this question proceeds in two steps. First, Table 2 shows that the correlation between Usefulness and hypothetical Use if not mandatory was 0.699 . In other words, Usefulness explained approximately $50 \%$ of the variance in Use if not mandatory. This is entirely consistent with results from the TAM studies, and suggests that, in this mandatory-use setting, Usefulness is tapping the same construct that DeLone and McLean sought to measure with Use. Second, the correlation between Usefulness and self-reported $I S$ Use $\%$ was only $0.295^{19}$. In addition, it is obvious from respondents' written comments (at the end of each questionnaire) that usage was determined by the needs of different departments, not by the desires of the users.

\footnotetext{
${ }^{18}$ One question was rephrased after the ten trials. This is why there are only 90 responses to the question concerning Use if not mandatory in Table 2.

${ }^{19}$ The reason these two variables are significantly correlated $(r=0.295, p=0.003)$ is probably because those who worked more hours per week with DAS viewed the system as more important $(r=0.415, p<0.000)$ and as will be shown shortly, more important systems are viewed as more useful. Correlations between IS Use \% and the other success measures in Table 2 are low.
} 
Table 1: Descriptive Statistics

\begin{tabular}{|c|c|c|c|c|c|c|c|c|c|}
\hline Yarable : & Mera & Sil: & Hitstogram & Min & Max & $\begin{array}{l}\text { Kunt } \\
\text { osis }\end{array}$ & $\begin{array}{l}\text { S.E. } \\
\text { Kurt }\end{array}$ & $\begin{array}{l}\text { Skew- } \\
\text { ness }\end{array}$ & $\begin{array}{l}\text { S.E. } \\
\text { Skew }\end{array}$ \\
\hline $\begin{array}{l}\text { 1. System } \\
\text { Quality }\end{array}$ & 4.21 & 1.46 & & 1.29 & 7.00 & -.89 & 0.48 & .05 & 0.24 \\
\hline $\begin{array}{l}\text { 2. Information } \\
\text { Quality }\end{array}$ & 4.66 & 1.29 & & 1.60 & 7.00 & -.60 & 0.48 & -.34 & 0.24 \\
\hline $\begin{array}{l}\text { 3. System } \\
\text { Importance }\end{array}$ & 4.76 & 1.42 & & 1.00 & 7.00 & -.26 & 0.48 & -.40 & 0.24 \\
\hline 4. Usefulness & 3.92 & 1.87 & & 1.00 & 7.00 & -1.02 & 0.48 & .04 & 0.24 \\
\hline 5. Satisfaction & 4.67 & 1.58 & & 1.00 & 7.00 & -.34 & 0.48 & -.58 & 0.24 \\
\hline $\begin{array}{l}\text { 6. Use if not } \\
\text { mandatory }\end{array}$ & & 2.19 & & 1.00 & 7.00 & -1.39 & 0.50 & -.22 & 0.25 \\
\hline 7. IS Use $\%$ & 20.1 & 21.4 & 网 & $0 \%$ & $95 \%$ & 2.50 & 0.49 & 1.72 & 0.24 \\
\hline
\end{tabular}

Table2: Reliabilities (Cronbach alpha) and Pearson Correlation Matrix (two-tailed test, significance in brackets, Spearman correlations very similar)

\begin{tabular}{|c|c|c|c|c|c|c|c|c|c|}
\hline Variable & $\begin{array}{l}\text { Yalid } \\
\text { Obs: }\end{array}$ & $\begin{array}{l}\text { No: of } \\
\text { itens. }\end{array}$ & $\begin{array}{l}\text { Cron } \\
\text { bach }\end{array}$ & 1 & 2 & 3 & 4 & 5 & 6 \\
\hline $\begin{array}{l}\text { 1. System } \\
\text { Quality }\end{array}$ & 101 & 7 & 0.935 & & & & & & \\
\hline $\begin{array}{l}\text { 2. Information } \\
\text { Quality. }\end{array}$ & 100 & 10 & 0.951 & $\begin{array}{l}.549 \\
(.000)\end{array}$ & & & & & \\
\hline $\begin{array}{l}\text { 3. System } \\
\text { Importance }\end{array}$ & 101 & 5 & 0.885 & $\begin{array}{l}.409 \\
(.000)\end{array}$ & $\begin{array}{l}.315 \\
(.001)\end{array}$ & & & & \\
\hline 4. Usefulness & 100 & 6 & 0.986 & $\begin{array}{l}.644 \\
(.000)\end{array}$ & $\begin{array}{l}.546 \\
(.000)\end{array}$ & $\begin{array}{l}.623 \\
(.000)\end{array}$ & & & \\
\hline 5. Satisfaction & 101 & 4 & 0.921 & $\begin{array}{l}.708 \\
(.000)\end{array}$ & $\begin{array}{l}.754 \\
(.000)\end{array}$ & $\begin{array}{l}.438 \\
(.000)\end{array}$ & $\begin{array}{l}.713 \\
(.000)\end{array}$ & & \\
\hline $\begin{array}{l}\text { 6. Use if not } \\
\text { mandatory }\end{array}$ & 90 & 1 & - & $\begin{array}{l}.603 \\
(.000)\end{array}$ & $\begin{array}{l}.478 \\
(.000)\end{array}$ & $\begin{array}{l}.631 \\
(.000)\end{array}$ & $\begin{array}{l}.699 \\
(.000)\end{array}$ & $\begin{array}{l}.572 \\
(.000)\end{array}$ & \\
\hline 7. IS Use \% & 97 & 1 & - & $\begin{array}{l}.260 \\
(.010)\end{array}$ & $\begin{array}{l}.105 \\
(.309)\end{array}$ & $\begin{array}{l}.415 \\
(.000)\end{array}$ & $\begin{array}{l}.295 \\
(.003)\end{array}$ & $\begin{array}{l}.169 \\
(.098)\end{array}$ & $\begin{array}{l}.283 \\
(.008)\end{array}$ \\
\hline
\end{tabular}

\section{Results: Use versus Usefulness}

In our opinion, the high correlation of Usefulness with Use if not mandatory, and the low correlations between the various perceptual success measures of IS Success and actual mandatory IS Use \% provide quite strong empirical support for DeLone and McLean's argument that when measuring IS Success, "usage, either perceived or actual, is only pertinent when such use is voluntary" $(1992, p .68)$. The remainder of this analysis therefore proceeds on the understanding that when usage is mandatory, Usefulness is the most appropriate usage-related measure of IS Success. 


\section{Results: Path Analysis}

Results from path analysis of the model in Figure 2 are reported in Table 3. Path coefficients in column 4 were computed using two ordinary least squares (OLS) linear regressions, the first with Usefulness as the dependent variable (Hypotheses 6, 3, and 4), and the second with User Satisfaction as the dependent variable (Hypotheses $7,2,1$, and 5). Path coefficients in column 5 were calculated using maximum likelihood estimation in the structural equation modelling (SEM) package called $\mathrm{Amos}^{20}$. To avoid reliance on any assumptions of multivariate normality, standard errors in column 5 were calculated using bootstrap simulation with 1,000 replications ${ }^{21}$. The path coefficients from the two methods of analysis are very similar, although the $t$-statistics for the SEM in column 5 are considerably lower than those for OLS regression.

The reason for including two sets of path coefficients (OLS and SEM) in Table 3 is that structural equation modeling is becoming much more common in the Information Systems literature (e.g., LISREL: Adams et al. 1992, Segars and Grover 1993, Chin and Todd 1995; PLS: Rivard and Huff 1988, Thompson et al. 1991 \& 1994, Igbaria et al. 1995), and many researchers probably wonder how the two/three methods of analysis compare. Most studies opt for just one method of analysis, a decision that leaves the reader without any basis for gaining an intuitive understanding of the relative merits of one method over another. Hence the two columns in Table 3. A detailed comparison of the techniques used for calculating the OLS and SEM path coefficients is presented in Appendix 1.

Despite the differences in analysis techniques, it is apparent from Table 3 (and Figure 3, which presents the results graphically) that for this particular data set, the conclusions one would draw from either analysis technique are the same. The results in Table 3 provide quite strong support for five of the hypotheses in Figure 2. The t-statistics in columns 4 and 5 are so large that we have confidence in rejecting the null hypotheses (of no association between the constructs) for hypotheses 1, 2, 3, 5, and 6. Support for hypothesis 4 was weaker, however, and after controlling for the effect of Importance on Usefulness there is no support for hypothesis 7. With the benefit of hindsight, one can see that the lack of significance in hypothesis 7 is consistent with the difficulties with our theoretical analysis (see end of the hypothesis development section). Perhaps Kappelman and McLean's correlation was so highly significant $(p<0.001)$ because the systems they studied were all working well -- the "Importance up, Satisfaction up" case discussed in the development of hypothesis 7 .

\section{CONCLUSIONS}

For the individual user of a specific information system, our results provide considerable support for the upstream side of DeLone and McLean's model of IS success. In effect, DeLone and McLean's model may be interpreted as saying that User Satisfaction is a response to three types of user aspirations for an information system: Information Quality (H1), System Quality (H2), and Usefulness (H5). As DeLone and McLean predicted, these three factors explained a large proportion of variance in User Satisfaction (over $70 \%$ in this study).

\footnotetext{
${ }^{20}$ Amos' coefficients are claimed to be almost identical -- equal to three decimal places -- to those from Jöreskog and Sörbom's (1988) LISREL.

21 "Bootstrap simulation" means randomly selecting different combinations of 100 records from the 100 observations. Sampling is with replacement, so in a given bootstrap sample of 100 records, some records will be selected more than once and other records will not be selected at all. Typically, about 60 distinct records appear in each sample. In some samples, some records may appear as many as five times.
} 
Table 3: Path Coefficients for the Model in Figure 2

(1)

\begin{tabular}{|c|c|c|}
\hline 1 & 8? & \\
\hline & from & to $17.2 \%$ \\
\hline
\end{tabular}

\begin{tabular}{|l|l|l|}
\hline H6 & System Importance & Usefulness \\
\hline
\end{tabular}

\begin{tabular}{l|l|l|}
\hline H3 & System Quality & Usefulness \\
\hline H4 & Information Quality & Usefulness
\end{tabular}

$\mathbf{R}^{2}$ for regression with Usefulness as dependent variable
(4)

(5)

\begin{tabular}{|l|l|}
$\begin{array}{l}\text { OLS regression } \\
\text { (using SPSS) } \\
(\mathrm{n}=98)\end{array}$ & $\begin{array}{l}\text { Structural equation } \\
\text { modeling (in Amos) } \\
(\mathrm{n}=100)\end{array}$ \\
\hline 0.427 & 0.449 \\
$(6.028)^{* * *}$ & $(4.777)^{* * *}$ \\
\hline 0.336 & 0.332 \\
$(4.169)^{* * *}$ & $(3.648)^{* * *}$ \\
\hline 0.225 & 0.214 \\
$(2.927)^{* *}$ & $(2.326)^{*}$ \\
\hline 0.612 (Adj $=0.600)^{*}$ & 0.628 \\
\hline
\end{tabular}

\begin{tabular}{|c|c|c|c|c|}
\hline H7 & System Importance & User Satisfaction & $\begin{array}{l}0.010 \\
(0.149) \mathrm{ns}\end{array}$ & $\begin{array}{l}0.013 \\
(0.383) \mathrm{ns}\end{array}$ \\
\hline $\mathrm{H} 2$ & System Quality & User Satisfaction & $\begin{array}{l}0.266 \\
(3.674) * * *\end{array}$ & $\begin{array}{l}0.285 \\
(3.132) * *\end{array}$ \\
\hline $\mathrm{H} 1$ & Information Quality & User Satisfaction & $\begin{array}{l}0.451 \\
(6.798) * * *\end{array}$ & $\begin{array}{l}0.463 \\
(5.861) * * *\end{array}$ \\
\hline $\mathrm{H} 5$ & Usefulness & User Satisfaction & $\begin{array}{l}0.287 \\
(3.396) * * *\end{array}$ & $\begin{array}{l}0.263 \\
(2.267) * * \\
\end{array}$ \\
\hline \multicolumn{3}{|c|}{$\begin{array}{l}\mathrm{R}^{2} \text { for regression with User Satisfaction as } \\
\text { dependent variable. }\end{array}$} & (Adj. $=0.727)$ & 0.781 \\
\hline \multicolumn{4}{|c|}{$\begin{array}{l}\text { Chi-square per degree of freedom } \\
\text { Adjusted goodness of fit index } \\
\text { Root mean square residual }\end{array}$} & $\begin{array}{l}880 / 454=1.94 \\
0.63 \\
0.19\end{array}$ \\
\hline
\end{tabular}

Rows in the above table are sequenced to correspond with Figures 2 and 3. Path coefficients and critical values for the structural equation modeling, column 5, were estimated using 1,000 "bootstrap" samples (see text). Tstatistics/critical values are in brackets. Significance levels are based on one-tailed tests because all path coefficients are expected to be positive.

${ }^{* * *} \mathrm{p}<0.001,{ }^{* *} \mathrm{p}<0.01,{ }^{*} \mathrm{p}<0.05, \mathrm{~ns}=$ not significant 
(a) $0.427^{* * *}$

(b) $0.449 * * *$

Importance of the system

(a) $0.015 \mathrm{~ns}$

(b) 0.010 ns

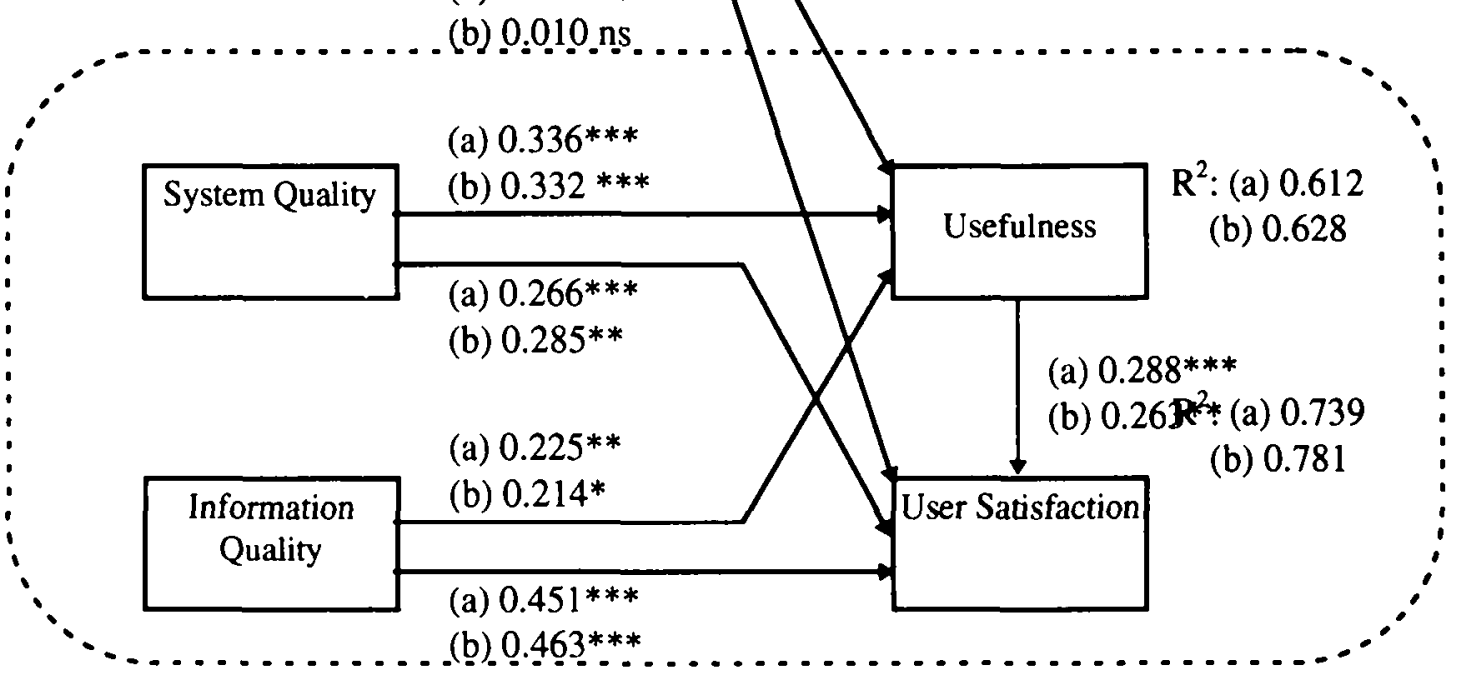

Figure 3: Results of Path Analysis

Case (a): Analysis using OLS regression in SPSS, $\mathrm{n}=98$ (listwise deletion of missing)

Case (b): Analysis using structural equation modelling in Amos (like LISREL), $n=100$

Significance levels: ${ }^{* * *} p<0.001,{ }^{* *} p<0.01,{ }^{*} p<0.05$, ns $=$ not significant

To the best of our knowledge, no prior research has identified the importance of the Importance of the task construct to a system's Perceived Usefulness and Use. Importance of the task is independent of the system, yet as shown in Figure 3, it has a major influence on Perceived Usefulness. Future research, both in the prediction of information system use (via Usefulness), and in the investigation of links between User Participation, User Involvement ${ }^{22}$ and system success (Barki and Hartwick 1994, Hartwick and Barki 1994), will need to control for the Importance of task performed by the system. For instance, it is not level of User Involvement that matters in User Participation research. It is the change in Involvement (the change in the perceived importance of a system as a result of Participation) that matters.

If researchers are looking for a simple, short measure of IS success, which one should they choose? DeLone and McLean argued that multiple indicators of success are required. To some extent, we agree. IS Success can mean many things to many people, and researchers must measure the IS success outcomes that are relevant to their own research goals. But as Satisfaction appears to be the most inclusive of the four perceptual measures investigated in this study, if a single measure is required, we recommend using User Satisfaction as the most general-purpose perceptual measure of system success. The four questions from Seddon and Yip (1992), which returned reliability coefficients (alpha) of 0.95 in their survey, and 0.92 in this study, may be all that is needed $^{23}$. Researchers wanting to understand why users are dissatisfied with their systems will probably find it helpful to measure at least the three causal constructs suggested by our slightly-modified DeLone and McLean model, namely, Information Quality, System Quality/Ease of Use, and Usefulness. When measuring Usefulness, it will of course be necessary to control for Importance of the task.

\section{REFERENCES}

Adams, D.A., R.R. Nelson, \& P.A. Todd (1992) "Perceived usefulness, ease of use, and usage of information technology: a replication", MIS Quarterly June, pp.227-247.

${ }^{22}$ Recall, Barki and Hartwick $(1989,1994)$ define User Involvement as the Importance and Personal

Relevance of the system.

${ }^{23}$ One of the present authors is presently attempting to develop an even more general measure. 
Arbuckle, J.L (1994a). Amos 3.51, Chicago, SmallWaters Corp (smallwaters@ acm.org).

(1994b). "Advantages of model-based analysis of missing data over pairwise deletion", Presented at the RMD Conference on Causal Modeling, West Lafayette, Indiana.

Bailey, J.E. \& S.W. Pearson (1983) "Development of a tool for measuring and analyzing computer user satisfaction", Management Science 29, May, pp.519-529.

Barki, H. \& J. Hartwick (1989) "Rethinking the concept of user involvement", MIS Quarterly March, pp.5263.

(1994) "Measuring user participation, user involvement, and user attitude", MIS Quarterly March, pp.59-79.

Baroudi, J.J., M.H. Olson, \& B. Ives (1986) "An empirical study of the impact of user involvement on system usage and information satisfaction", Communications of the ACM 29, March, pp.232-238.

Baroudi, J.J. \& W.J. Orlikowski (1988) "A short-form measure of user information satisfaction: a psychometric evaluation and notes on use", Journal of MIS 4, Spring, pp.44-59.

Bollen, K.A (1989) Structural Equations with Latent Variables New York, Wiley.

Chin, W.W. \& P.A. Todd (1995) "On the use, usefulness, and ease of use of structural equation modeling in MIS research: a note of caution", MIS Quarterly 19, 2, June, pp.237-246.

Davis, F.D. (1989) "Perceived usefulness, perceived ease of use, and user acceptance of information technology", MIS Quarterly 13 September, pp.319-340.

(1993) "User acceptance of information technology: system characteristics, user perceptions, and behavioral impacts", Int. J. Man-Machine Studies 38, March, pp.475-487.

, R.P. Bagozzi, \& P.R. Warsaw (1989) "User acceptance of computer technology: a comparison of two theoretical models", Management Science 35, August, pp.982-1003.

DeLone, W.H. \& E.R. McLean (1992) "Information systems success: the quest for the dependent variable", Information Systems Research 3, March, pp.60-95.

Doll, W.J. \& G. Torkzadeh (1988) "The measurement of end-user computing satisfaction", MIS Quarterly 12, June, pp.259-274.

Franz, C.R. \& D. Robey (1986) "Organizational contexts, user involvement and the usefulness of information systems", Decision Sciences 17, pp.329-356.

Galletta, D.F (1986) "A longitudinal view of an office system failure", SIGOA Bulletin 7, pp.7-11.

\& A.L. Lederer (1989) "Some cautions of the measurement of user information satisfaction", Decision Sciences Summer, pp.419-438.

Goodhue, D.L (1986) "IS attitudes: toward theoretical and definitional clarity", Proceedings of the Seventh International Conference on Information Systems, 181-194.

\& R.L. Thompson (1995) "Task-technology fit and individual performance", MIS Quarterly 19, June, pp.213-236.

Hartwick, J. \& H. Barki (1994) "Explaining the role of user participation in information system use", Management Science 40, April, pp.440-465.

Igbaria, M., T. Guimaraes, \& G.B. Davis (1995) "Testing the determinants of microcomputer usage via a structural equation model", Journal of MIS, 11, 4, Spring, pp.87-114.

Ives, B. \& M.H. Olson (1984) "User involvement and MIS success: a review of research", Management Science 30, May, pp.586-603.

Ives, B., M.H. Olson, \& J.J. Baroudi (1983) "The measurement of user information satisfaction", Communications of the ACM 26 October, pp.785-793.

Jackson, C.M., S. Chow, \& R.A. Leitch (1993) "Toward an Understanding of the Behavioral Intention to Use an Accounting Information System", Working paper, Boston University School of Management, May.

Jenkins, A.M. \& J.A. Ricketts (1979) "Development of an instrument to measure user information satisfaction with management information systems", Working paper, Indiana University, Bloomington November.

Jöreskog, K.G. \& D. Sörbom (1988) LISREL 7: A Guide to the Program and Applications. Chicago, SPSS Inc.

Kappelman, L.A. \& E.R. McLean (1991) "The respective roles of user participation and user involvement in information system implementation success", Proceedings of the International Conference on Information Systems, pp.339-349.

Kraemer, K.L., J.N. Danzinger, D.E. Dunkle, \& J.L. King (1993) "The usefulness of computer-based information to public managers", MIS Quarterly June, pp.129-148.

Larcker, D.F. \& V.P. Lessig (1980) "Perceived usefulness of information: a psychometric examination", Decision Sciences 11, pp.121-134. 
Lawler, E.E. \& T.H. Douglas (1970) "Relationship of Job Characteristics to Job Involvement, Satisfaction, and Intrinsic Motivation", Journal of Applied Psychology, 54, August, pp.305-312.

Melone, N.P (1990) "A theoretical assessment of the user satisfaction construct in information systems research", Management Science 36, pp.1-16.

Miller, J. \& B.A. Doyle (1987) "Measuring the effectiveness of computer-based information systems in the financial services sector", MIS Quarterly 11, pp.107-124.

Naylor, J.C., R.D. Prichard, \& D.R. Ilgen (1980) A Theory of Behavior in Organizations. Academic Press.

Rivard. S. \& S.L. Huff (1988) "Factors of success for end user computing". Communications of the ACM, 29, 5, May, pp.486-501.

Schewe C.D. (1976) "The management information system user: An exploratory behavioral analysis", Academy of Management Journal 19, pp.577-590.

Seddon, P.B. \& S.K. Yip (1992) "An empirical evaluation of user information satisfaction UIS, measures for use with general ledger accounting software", Journal of Information Systems, 75-92.

Segars, A.H. \& V. Grover (1993) "Re-examining perceived ease of use and usefulness", MIS Quarterly 17, 4, December, pp.517-525.

Siegel, S. \& N.J. Castellan (1988) NonParametric Statistics. 2d ed. McGraw-Hill.

Thompson, R.L., C. Higgins, \& J.M. Howell (1991) "Personal computing: towards a conceptual model of utilization", MIS Quarterly, 15,1 March, pp.125-143.

(1994) "Influence of experience on personal computer utilization: testing a conceptual model", Journal of Management Information Systems 11,1 Summer, pp.167-187.

Treacy, M.E (1985) "An empirical examination of a causal model of user information satisfaction", Center for Information Systems Research, Sloan School of Management, MIT April.

Zaichkowski, J.L (1985) "Measuring the involvement construct", Journal of Consumer Research 12, pp.341352. 


\section{APPENDIX 1: COMPARISON OF ORDINARY LEAST SQUARES (OLS) REGRESSION AND STRUCTURAL EQUATION MODELING (SEM)}

To the non-statistician, the advantages of structural-equation models (SEM) over conventional factor analysis and ordinary-least-squares (OLS) regression techniques are unclear. Bollen (1989, page v) describes the advantages of LISREL-style SEM in the following rather vague terms:

(Structural equation models) ... are regression equations with less restrictive assumptions that allow measurement error in the explanatory as well as the dependent variables. They consist of factor analyses that permit direct and indirect effects between factors. They routinely include multiple indicators and latent variables. In brief, these models encompass and extend regression, econometric, and factor analysis procedures.

So, how much difference is there between OLS and LISREL-style SEM? Do these differences matter? In the case of the present data set, the principal differences between the two sets of path coefficients in columns 4 and 5 in Table 3 (in the main paper) are as follows:

First, for the OLS regression, the score for each latent variable (theoretical construct) is the mean of responses to the questions used to measure the variable ${ }^{24}$. For example, for any one respondent, the score for the latent variable called User Satisfaction is calculated as the mean of that respondent's responses to the four questions shown in the Appendix 2. The Cronbach alpha of 0.92 in Table 1 indicates that for the sample as a whole (100 observations), scores for these four questions tended to vary together very consistently. OLS then assumes these average latent variable scores for the independent variables are measured without error, and minimizes the squared difference between the dependent variable's average latent variable scores and the scores predicted by the regression equation.

By contrast, in LISREL-like SEM, no scores are calculated for any latent variables, dependent or independent. Instead, scores on individual questions are used to calculate the covariance between each question and every other question. Amos then uses a combination of the researcher's path diagram and maximum likelihood estimation to minimize the difference between the sample covariance matrix and that implied by the path diagram. In Figure 4, the rectangles represent responses to individual questions, and the ovals represent the latent variables. "Loadings" of each question (rectangle) on its underlying latent variable (oval) are the result of this covariance-matrix-fitting process ${ }^{25}$. The chi-square coefficient reported by Amos (chi-sq. $=880, \mathrm{df}=454$, chi-sq/df $=1.94)$ is the extent of misfit between the sample and estimated covariance matrices. There is a large misfit. The adjusted goodness of fit index for this model is only 0.63 (root mean square residual $=0.19$ ), but as we have no strong theoretical grounds for re-specifying the model, we have not attempted to "tune" the model to increase the goodness of fit.

Second, for the OLS regression, missing values are handled either by the averaging process or else the entire response is deleted (listwise deletion). In this study, if one respondent only answers three of four questions, the score for the latent variable for that respondent is the average of the three (not four as with the other respondents). If the researcher judges that too few questions have been answered for the mean of responses to be meaningful, the score for that respondent is left undefined (missing), and the entire response from that respondent is deleted by SPSS during listwise deletion of missing variables during estimation of the regression equation.

By contrast, in structural equation modeling, covariances from each question to every other question are required before model fitting can begin. Thus in SEM, the treatment of missing values is handled in during calculation of the sample covariance matrix. Amos provides a technique for such estimation (described in Arbuckle (1994b)), but when bootstrapping is used to obtain what Arbuckle describes as "more robust" estimates of standard errors (as in the data reported in Table 3, column 5) this missing-value treatment is not available. Thus for the data in Table 3 , missing values for particular questions were replaced by means for the respective questions.

Such mean replacement of missing values occurred for data from only 2 of the 100 respondents. (These two responses were also those deleted in SPSS during its listwise deletion phase.) A total of 17 missing values from $32 * 100=3,200$ respondent answers $(0.53 \%)$ were replaced. The effect on the covariance of replacing missing

\footnotetext{
${ }^{24}$ An indication of the degree to which these questions tap the one underlying construct is given by Cronbach's alpha coefficient.

${ }^{25}$ The smallest loading is 0.69 between the latent variable infoqual and question iq6 in the bottom left of Figure 4. The 0.48 to the left of the iq6 rectangle is the variance in iq 6 explained by infoqual, i.e., $0.69^{2}$.
} 
values by the mean of the remaining observations for a given question is entirely neutral. To see this, consider the formula for calculating covariance between responses to two questions $X_{1}$ and $X_{2}$ :

$\operatorname{cov}\left(X_{1}, X_{2}\right)=\frac{\sum_{i=1}^{N}\left(X_{1 i}-\overline{X_{1}}\right)\left(X_{2 i}-\overline{X_{2}}\right)}{N-1}$, where $\overline{X_{j}}=$ sample mean for Q. $j, j=1,2$

In this case, because 100 people responded, calculation of the covariance involves a summation of 100 terms of the form $\left(X_{1 i}-\overline{X_{1}}\right)\left(X_{2 i}-\overline{X_{2}}\right)$. Suppose the person completing the $88^{\text {th }}$ questionnaire did not answer question $X_{2}$, and that the missing score for this question was replaced by the mean of all other respondents' scores for $\mathrm{X}_{2}$, i.e., by $\overline{X_{2}}$. This means the $88^{\text {th }}$ of the 100 terms being summed to calculate the covariance would be zero (because $\left(X_{288}-\overline{X_{2}}\right)=\left(\overline{X_{2}}-\overline{X_{2}}\right)=0$ ). Thus the covariance is determined from the other 99 observations, and the mean-substituted $88^{\text {th }}$ observation has no effect on the calculation of the numerator of the covariance 


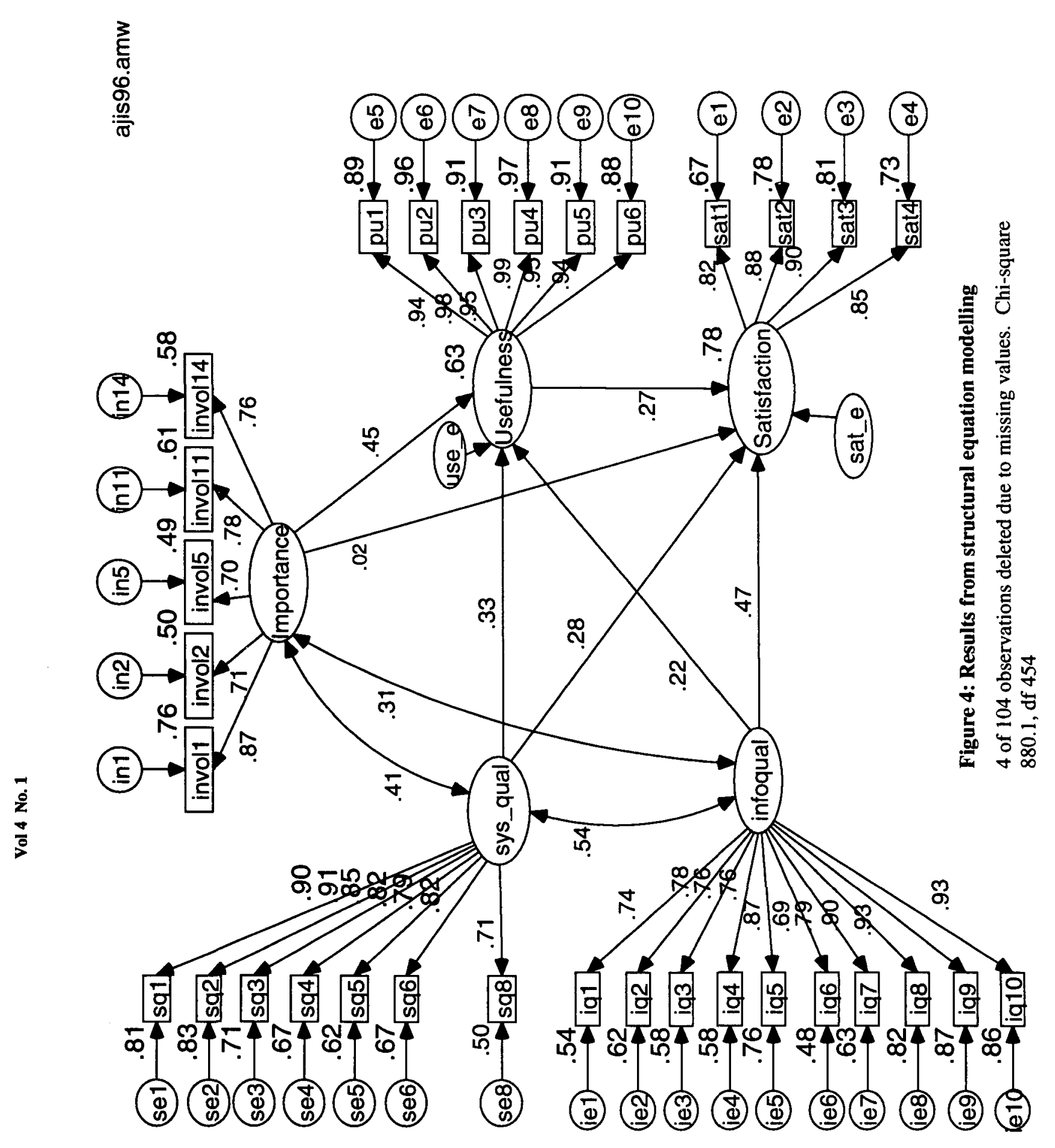


Appendix 2: Departmental Accounting System (DAS) Evaluation Questionnaire

Please circle the appropriate number

Part A: System Quality. strongly agree strongly disagree

1. DAS is easy to use.

2. DAS is user friendly.

3. Compared to other computer software, DAS is easy to learn. $\begin{array}{lllllll}1 & 2 & 3 & 4 & 5 & 6 & 7\end{array}$

4. I find it easy to get DAS to do what I want it to do.

5. It is easy for me to become skilful at using DAS.

6. I believe that DAS is cumbersome to use.

7. My using DAS require a lot of mental effort.

8. Using DAS is often frustrating.

$\begin{array}{lllllll}1 & 2 & 3 & 4 & 5 & 6 & 7\end{array}$

$\begin{array}{lllllll}1 & 2 & 3 & 4 & 5 & 6 & 7\end{array}$

$\begin{array}{lllllll}1 & 2 & 3 & 4 & 5 & 6 & 7\end{array}$

$\begin{array}{lllllll}1 & 2 & 3 & 4 & 5 & 6 & 7\end{array}$

$\begin{array}{lllllll}1 & 2 & 3 & 4 & 5 & 6 & 7\end{array}$

$\begin{array}{lllllll}1 & 2 & 3 & 4 & 5 & 6 & 7\end{array}$

Part B: Information Quality.

For the system overall,

1. Do you think the output is presented in a useful format?

2. Are you satisfied with the accuracy of the system ?

3. Is the information clear?

4. Is the system accurate?

5. Does the system provide sufficient information?

6. Does the system provide up-to-date information?

7. Do you get the information you need in time?

8. Does the system provide reports that seem to be just about exactly what you need?

9. Does the system provide the precise information you need ?

10. Does the information content meet your needs?

\begin{tabular}{ccccccc}
\multicolumn{1}{l}{ never } & & & \multicolumn{3}{c}{ always } \\
1 & 2 & 3 & 4 & 5 & 6 & 7 \\
1 & 2 & 3 & 4 & 5 & 6 & 7 \\
1 & 2 & 3 & 4 & 5 & 6 & 7 \\
1 & 2 & 3 & 4 & 5 & 6 & 7 \\
1 & 2 & 3 & 4 & 5 & 6 & 7 \\
1 & 2 & 3 & 4 & 5 & 6 & 7 \\
1 & 2 & 3 & 4 & 5 & 6 & 7 \\
1 & 2 & 3 & 4 & 5 & 6 & 7 \\
1 & 2 & 3 & 4 & 5 & 6 & 7 \\
1 & 2 & 3 & 4 & 5 & 6 & 7
\end{tabular}

Part C: Overall Satisfaction.

On the following scales, please circle the number which best reflects your overall satisfaction with $D A S$.

1. How adequately do you feel DAS meets the information processing needs of your area of responsibility?

2. How efficient is DAS ?

3. How effective is DAS ? $\begin{array}{lllllllll}\text { adequate } & I & 2 & 3 & 4 & 5 & 6 & 7 \text { inadequate }\end{array}$

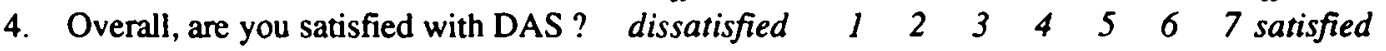

Part D: Perceived Usefulness.

On the following scales, please circle the number that best reflects how useful you perceive DAS to be.

disagree

strongly agree strongly

1. Using DAS in my job enables me to accomplish my tasks more quickly. $\quad \begin{array}{lllll}1 & 2 & 3 & 4 & 5\end{array}$ 6

2. Using DAS improves my job performance.

3. Using DAS in my job increases my productivity.

4. Using DAS enhances my effectiveness in the job.

5. Using DAS makes it easier to do my job.

6. Overall, I find DAS useful to my job.

$\begin{array}{lllllll}7 & & & & & & \\ 1 & 2 & 3 & 4 & 5 & 6 & 7 \\ 1 & 2 & 3 & 4 & 5 & 6 & 7 \\ 1 & 2 & 3 & 4 & 5 & 6 & 7 \\ 1 & 2 & 3 & 4 & 5 & 6 & 7 \\ 1 & 2 & 3 & 4 & 5 & 6 & 7\end{array}$

\section{Part E: Importance of the system}

(presented to respondents as questions about their Involvement with DAS).

4. For me personally, in my job, DAS is

$\begin{array}{lllllllll}\text { unimportant } & 1 & 2 & 3 & 4 & 5 & 6 & 7 & \text { important } \\ \text { relevant } & 1 & 2 & 3 & 4 & 5 & 6 & 7 & \text { irrelevant } \\ \text { trivial } & 1 & 2 & 3 & 4 & 5 & 6 & 7 & \text { fundamental } \\ \text { essential } & 1 & 2 & 3 & 4 & 5 & 6 & 7 & \text { non-essential } \\ \text { needed } & 1 & 2 & 3 & 4 & 5 & 6 & 7 & \text { not needed }\end{array}$




\section{Part F: Usage of the system}

disagree

strongly agree strongly

1. If DAS were not mandatory, I would still use it $\begin{array}{lllllll}1 & 2 & 3 & 4 & 5 & 6 & 7\end{array}$

2. On average, I spend approximately

3. This represents _ $\%$ of my work. hours/week working with DAS. 